\title{
Analysis of Heat Absorption and Collection Based on Solid Structures collector
}

\author{
Yan Liu ${ }^{\mathrm{a}, \mathrm{b}}$, Wenbin $\mathrm{Li}^{\mathrm{a}, \mathrm{b}}$, Qing Gao ${ }^{\mathrm{a}, \mathrm{b}, *}$, Yong Huang ${ }^{\mathrm{a}, \mathrm{b}}$, Peizhuo $\mathrm{Li}^{\mathrm{a}, \mathrm{b}}$, Yongzhen Wang ${ }^{\mathrm{a}, \mathrm{b}}$
}

a. State Key Laboratory of Automotive Simulation and Control, Jilin University, Changchun 130025, China

b. Department of Thermal Energy Engineering, Jilin University, Changchun 130025, China

\begin{abstract}
A solid structure, such as a road, building wall or envelop, used as a solar collector is considered an effective and new way to use renewable energy. This paper focused on the temperature characteristics of four structures exposed to sunshine: asphalt, red brick, composite cement and concrete road slab. Furthermore, the collected heat based on a hydraulic system was investigated experimentally. For the four structure slabs, their temperature differences are due to solar radiation absorption varied greatly by the material's heat absorptance and color. Through the test, asphalt slab attained the highest temperature and had the weakest reflection among the structures. Compared with the others, the temperature of the asphalt slab was greater by $8.1 \%, 14.9 \%$ and $16.4 \%$ than the brick, composite cement and concrete, respectively. The reflection intensity growth ratio was defined and indicates the growth potential for absorbing radiation in the solid slab surface. From the experiments, it was concluded that a suitable selection of road materials can greatly improve the thermal absorption, conduction and penetration into the solid slab. The collected heat capability was approximately $250 \mathrm{~W} / \mathrm{m}^{2}$ to $350 \mathrm{~W} / \mathrm{m}^{2}$ in the natural summer condition. A black coating or a surface modification can collect more heat, reaching greater than $250 \mathrm{~W} / \mathrm{m}^{2}$. The solar collecting heat efficiency with a surface configuration of the road slab can reach above $30 \%$ in the summer time.
\end{abstract}

Keywords: solar collection, solid structure, heat absorption analysis, collection heat analysis, reflection spectrum

\section{Introduction}

Solar energy is an inexhaustible and clean source of energy. Therefore, the collection and utilization of solar energy is an important measure to achieve sustainable development. Solar energy is mainly applied in the form of photovoltaic and solar thermal, the technology of photovoltaic has matured, and the key of solar thermal conversion technology is solar collector. For low temperature solar thermal application technology, there are two main forms of solar collectors, one is installed on the roof and the other is a solid collector combined with a solid. Examples are Castorvig Street in Hengelo [1], the sidewalk of the Dutch campus of Louisiana State University [3-4], the Leopold II Tunnel in Brussels [2], Provincial Road 306 in Mexico, and Maoyuan Road in Shanghai. Solid collectors[5] were first proposed when a patent was published in the United States in 1979, which described the use of roads and roofs as solar collectors. Since then, Chaurasia[6] has studied concrete solar collectors on roofs. In 1997, Yiping Gao[7] introduced the concept of snow melting on roads for solar energy applications for the first time in China and conducted theoretical and experimental studies on this concept with researchers from the Unification Institute. Their research mainly included solar energy collection by solid panels, snow and ice melting in winter, and the use of seasonal UTES hydraulic systems. E. Bilgen [8]conducted an experimental study of natural convection, radiation, and conduction in a horizontal concrete panel system, and their results showed that the incident energy on the concrete panels had little effect on the absorbed heat of the panels, and the radiant heat loss was about $60 \%$, while the natural convection-induced loss is $40 \%$. In the same year, some scholars introduced a hydraulic system in road bridges, which extracts solar radiation energy in summer, supplies seasonal underground thermal energy storage, and then uses hydraulic snow and ice melting in winter [9-11]. This is the earliest study about the integrated application of heat collection and cross-seasonal heat transfer in roadways.

In the five years following 2005, researchers began to work on the application of road solar collectors for ice and snow melting and inter-seasonal heat transfer technologies. In 2005, Gordon [12] showed that the combination of solid surface collectors and interseasonal heat transfer (IHT) technology allows the energy collected and stored

\footnotetext{
*Corresponding author, Qing Gao, Tel.: +86 431 85094241, fax: +86 43185682227.

E-mail address: 2697354604@qq.com
} 
in summer to be used to heat buildings and ice and snow melt in winter. Subsequently, the UK and the Netherlands[13] collaborated on the Road Energy Systems® (RES) asphalt solar collectors and the first pavement collector was successfully installed in June 2006 at Ullapool Scotland. 2008, Carder et al. [14] presented research results on inter-seasonal heat transfer systems using solar collectors on roads and shallow insulated heat banks on the ground, and they conducted a two-year monitoring of collector heat storage units constructed on actual roadways and presented a numerical model and lifetime cost for recovering heat for roadway winter maintenance. In the same year, Mallick et al. [15] conducted a study on enhanced solar collectors using asphalt pavements using experimental and modeling approaches, and the results showed that the pipe depth and pipe network arrangement are the keys to improve the heat collection capacity. Furthermore, based on the results of their modeling analysis, it is not difficult to find that reducing the reflectance on the pavement and increasing the absorption of the pavement can improve the heat collection efficiency.

As research progressed, people's studies were not limited to ice and snow melt and heat transfer across seasons, but researchers began to further explore some characteristics of asphalt pavement collectors. In 2011, Shaopeng $\mathrm{Wu}[16]$ studied the thermal response of asphalt pavement and found that the heat collection efficiency of asphalt pavement collectors could reach more than 33.3\%. In 2013, Vansea Bobes-jesus[17] on the previous work studied the thermal performance of asphalt and the influence of various variables in the heat collection process, proving that asphalt collectors can utilize low-grade solar energy. In 2014, P. Pascual-Muñoz et al.[18] found that the degradation performance ratios of two different asphalt mixtures differed significantly, and the degradation of color was accompanied by a decrease in heat collection capacity. In 2017, Alejandro Alonso-Estébanez[19] provided an idea to apply numerical techniques to characterize laboratory-scale asphalt solar collectors formed by different slabs. And experimental tests were performed to determine the thermal performance of the collectors for three values of heat exchange fluid flow rates. The results showed that the larger the value of heat exchange fluid flow rate, the better the thermal performance. Also, Richard O'hegarty[20] found that concrete solar collectors are a viable application for low temperature solar thermal technology. Anne Mäkiranta[21] and Caner Çuhac[22] found in their research that bitumen has a very high potential as a heat collecting material.

Some researchers have also studied collectors from a material perspective.Jose L. Concha [23] applied a self-healing asphalt mixture to collectors and found that this material increases heat transfer and storage. Catalin Daniel Galatanu [24] concluded that changes in the reflective properties of asphalt materials have a significant effect on solar pavement heat collection and proposed a measurement method for field conditions.

There is no doubt that asphalt pavement collectors are feasible. However, by studying the literature, we find that most of the current research has focused on how to improve the heat collection efficiency of asphalt pavement collectors, using asphalt pavement collectors to melt snow and ice, reduce urban heat island effect, and solar power generation. Although a few researchers have considered the effect of material properties on collectors, no specific analysis has been performed. In other words, there is a lack of research to determine the direct correlation between pavement materials and road collector performance, as well as to improve and optimize heat absorption and collection.

In order to choose the material and form of the road surface, it is necessary to compare solid collectors of different materials. One of the main objectives of this paper is to investigate the absorption and collection of solar radiation from the perspective of improving solid solar collectors. In order to investigate the effect of different solid materials on solar collectors, this paper compares the heat collection efficiency, the amount of heat collected, the surface temperature of the pavement plate, the bottom temperature of the pavement plate and the reflection spectrum of four structures of solar collectors: red brick, asphalt, composite cement and concrete. Based on this, the effects of three surface characteristics, namely rough, smooth and black coating, on heat collection were compared by setting up a control experiment. 


\section{Experiment and facilities}

This work contains two parts: experiments on heat absorption performance and experiments on heat collection performance. In the experiments of heat absorption performance, the effects of three factors, namely road materials (red brick, composite cement, concrete and asphalt), reflectance spectra of material surfaces and surface morphology, on heat collection capacity are analyzed; in the experiments of heat collection performance, the heat collection amount per unit area, heat collection efficiency and surface temperature of collectors of different materials under the same conditions (including: solar radiation intensity, operation parameters connected to piping works) are investigated In the experiments, we investigate the relationship between heat collection capacity per unit area, heat collection efficiency and surface temperature of collectors of different materials under the same conditions (including: solar radiation intensity, operation parameters and ductwork connection) and the relationship between them.

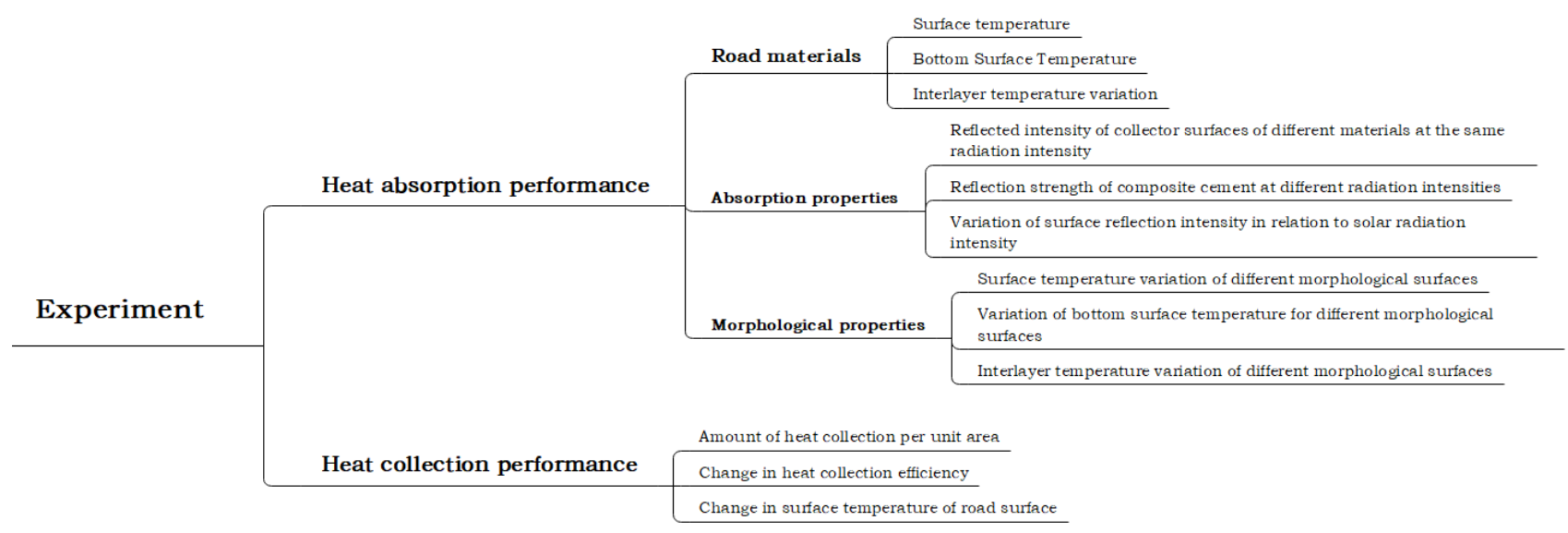

Fig. 1 Experiment content

To measure the heat absorption, four solid materials were selected as a slab cutting block in this experiment. The solar energy absorbability was determined by the surface temperature, and the reflection spectrum, and the characteristics of the absorbed thermal energy in each slab was studied.

The cutting block in the test is shown in Fig. 1. Four pieces of the test blocks had dimensions of $25 \mathrm{~cm} \times 32 \mathrm{~cm}$ with a thickness of $6.5 \mathrm{~cm}$, as shown in Fig. 2-a. The test blocks are composed of two layers, a roadbed layer and an adiabatic cushion layer, with thicknesses of $4.5 \mathrm{~cm}$ and $2.0 \mathrm{~cm}$, respectively, as shown in Fig. 2-b. Materials include asphalt, red brick, composite cement and concrete, which are labeled (1), (2), (3) and (4), respectively, as shown in Fig. 2-a and c. Therein, red brick is often used as pedestrian pavement for walking, and the composite cement is made by adding self-made black and highly conductive material into normal cement.

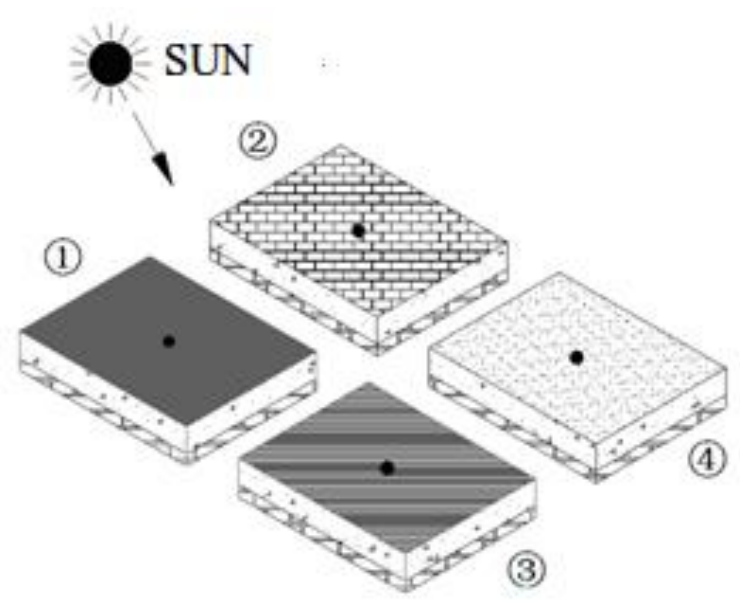

(a) Experimental Principle 


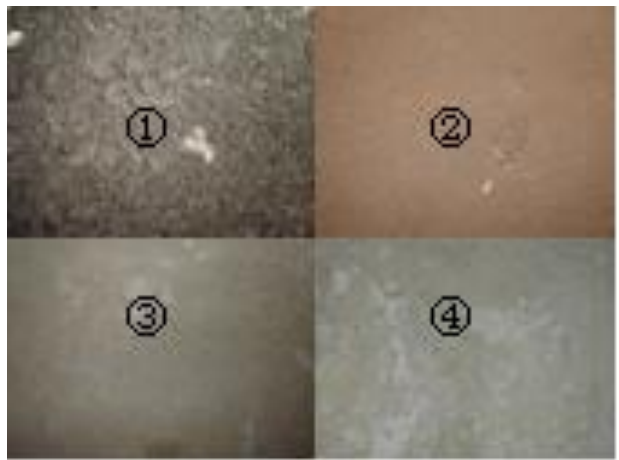

(b) Pavement material

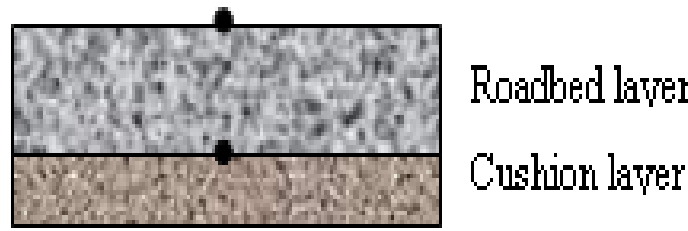

- Termerature russurement

(1)asphalt, (2)red brick, (3)composite cement, (4)concrete

Fig. 2 Experimental solid plate structure

The experiment was performed in outdoor environments, and the four test blocks were placed in identical conditions. The main measurement parameters are the solar radiation intensity, ambient temperature, surface and bottom temperatures of the roadbed, inlet and outlet temperatures of the working fluid, reflection spectrum, flow rate of the fluid, wind velocity, etc. The solar radiation intensity was measured by a Taiwan TES1333R solar light meter, the temperature was monitored by a K-type thermocouple and automatically recorded by a Japan Yokogawa MV200 video graphic recorder, and the spectrum was measured by a US Ocean Optics' HR4000 high-resolution optical spectrometer. Two temperature measurements on the test blocks were taken on the upper and bottom surface of the roadbed, as observed in Fig. 2-b. Both temperatures were used to describe the heat absorbability and express the heat conductivity of the roadbed.

For the heat from the solar collection system in the solid structure, experimental slabs were built with imbedded cement and pipes. There were three types of surfaces used, i.e., natural, smooth surface; black coating, smooth surface and grooved surface, as shown in Fig. 3. The black surface was treated by an outside coating. The hydronic pipes were arranged in serpentine form with a spacing of $100 \mathrm{~mm}$. The pipes were made from PE (Polyethylene) with an outside diameter of $22 \mathrm{~mm}$ and an inner diameter of $20 \mathrm{~mm}$.

In the test, cold water entered the slab to absorb solar energy and became hot. A heat exchanger was used to recover the temperature of the working water.

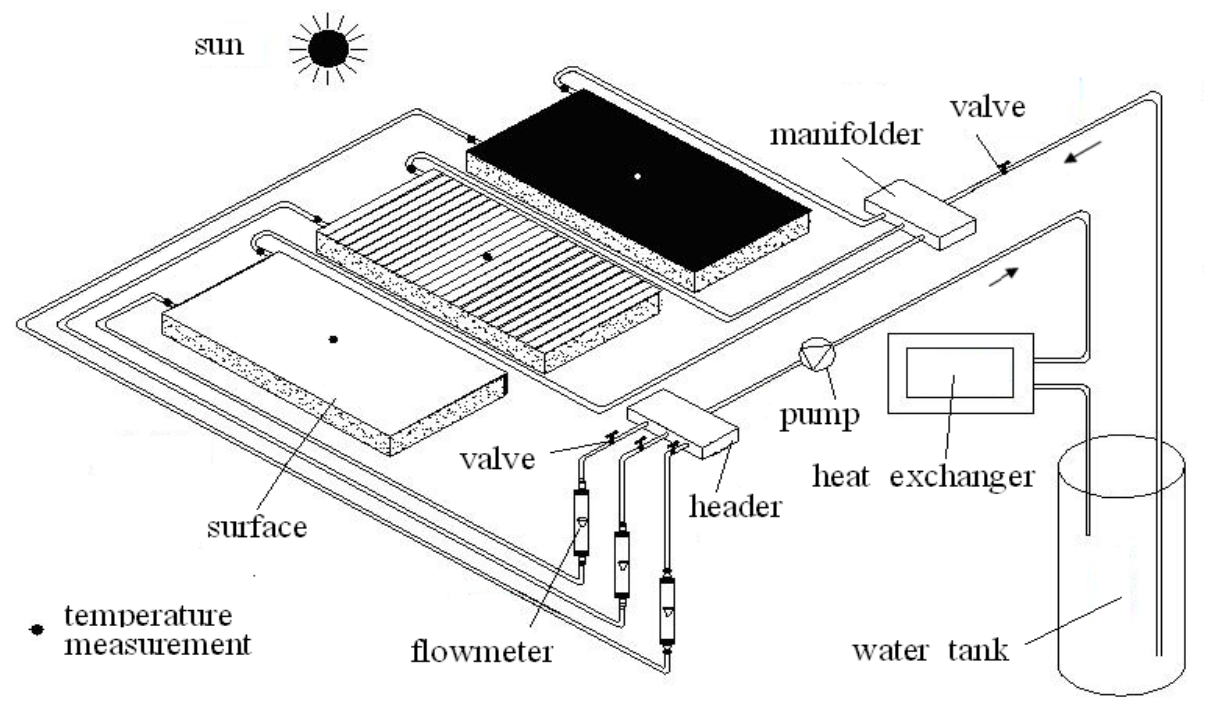

coil pipes

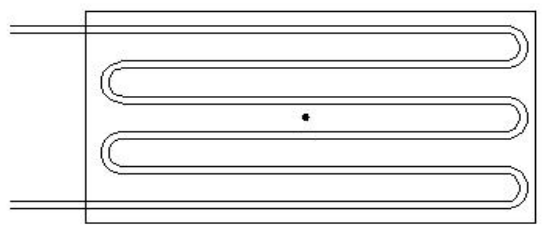

road layers

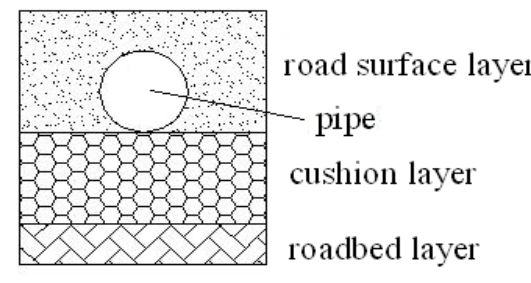

Fig. 3 Experimental system diagram

\section{Heat absorption analysis




\subsubsection{Experimental meteorological conditions}

The experiment was performed on August 9, 2009 in Changchun, which is located in northeast China. The ambient temperature and solar radiation intensity are shown in Fig. 4.

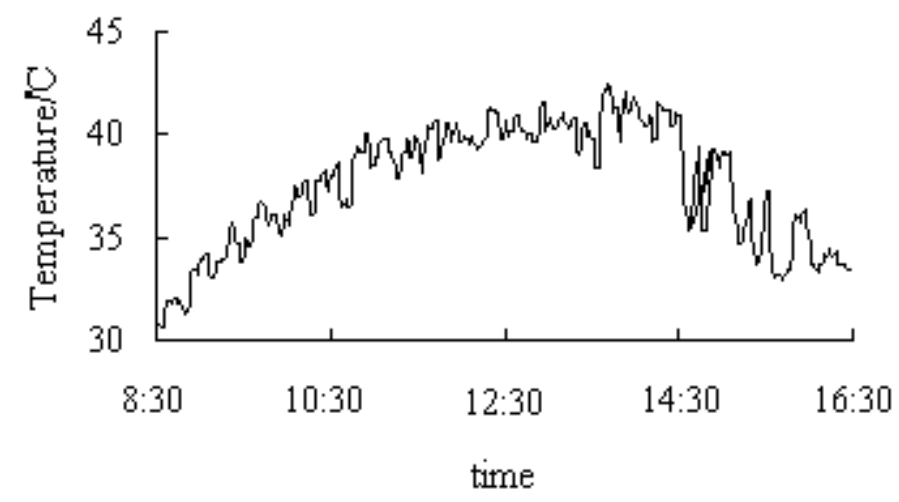

(a) Ambient temperature

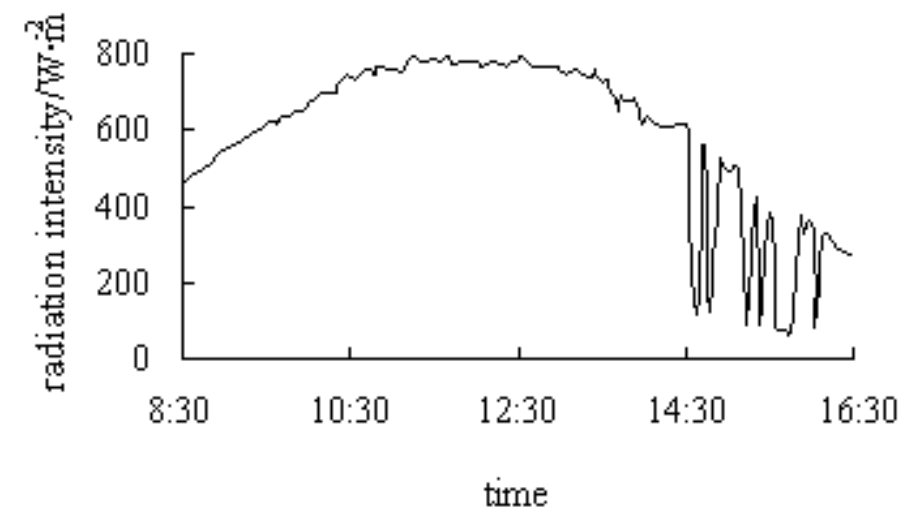

(b) Solar radiation intensity

Fig. 4 Ambient temperature and solar radiation intensity

From Fig. 4, the ambient temperature and solar radiation intensity increased at first and then decreased over time. Because of the impact of a floating cloud in the sky, several large fluctuations occurred in both the radiation and temperature curves. In fact, the ambient temperature was measured around the surrounding of slab and was also affected by outdoor wind. Thus, a wind shelter was used to avoid unwanted effects in the test.

\subsubsection{Temperatures in the roadbed}

Fig. 5 and Fig. 6 show the temperature variations of the upper and bottom roadbed layers over time. The upper temperature of the roadbed layer was the surface temperature of the slab. In the Fig. 5, following, temperature of upper surface and bottom surface increased at first and then dropped by the variation in the solar radiation intensity and ambient temperature. Essentially, the temperature peak values lagged behind the peak values of solar radiation intensity. This delay in the solar heat collection system of the slab is due to the large thermal capacity of the solid structure. By comparing the upper surface temperature with the bottom temperature, it is clear that the bottom temperature was delayed more behind the upper temperature. Furthermore, the peak surface temperature was $71.9^{\circ} \mathrm{C}$ in the asphalt slab, which is greater than that of the red brick slab, composite cement slab and the concrete slab by $5.8^{\circ} \mathrm{C}, 10.7^{\circ} \mathrm{C}$ and $11.8^{\circ} \mathrm{C}$, respectively. The peak bottom temperatures were lower than that of the surface temperature by $7.1^{\circ} \mathrm{C}, 4.9^{\circ} \mathrm{C}, 3.7^{\circ} \mathrm{C}$ and $4.3^{\circ} \mathrm{C}$ and occurred at 13:55 PM. A delay of nearly 40 min existed between the upper surface temperature and the bottom surface temperature. Clearly, the heat transfer delay are significantly affected by the thermal capacity and heat conduction ability of the roadbed, and the difference between them are caused by different materials. Therefore, it is important to pay more attention to the engineering design of a solid structure solar collector. 


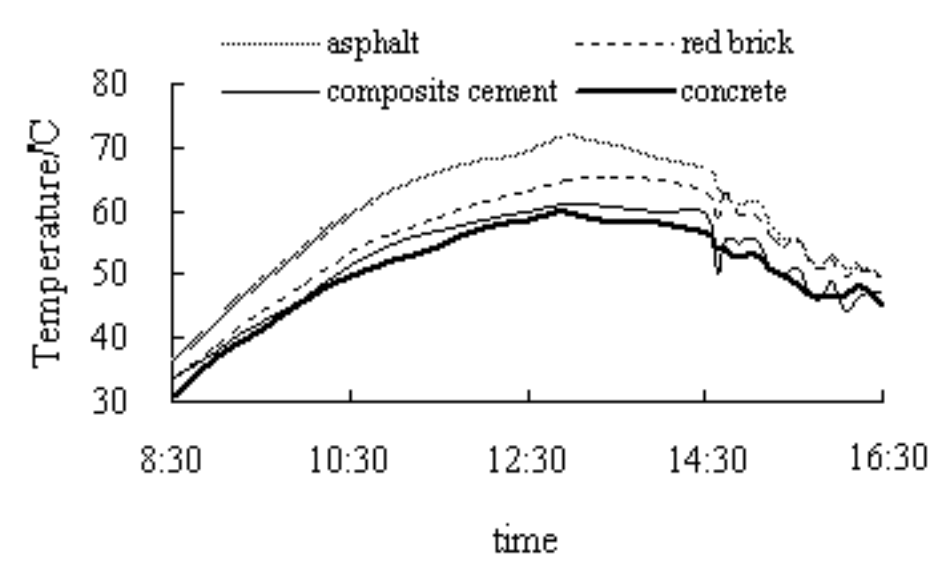

Fig. 5 Temperature variation graph of the road plate surface

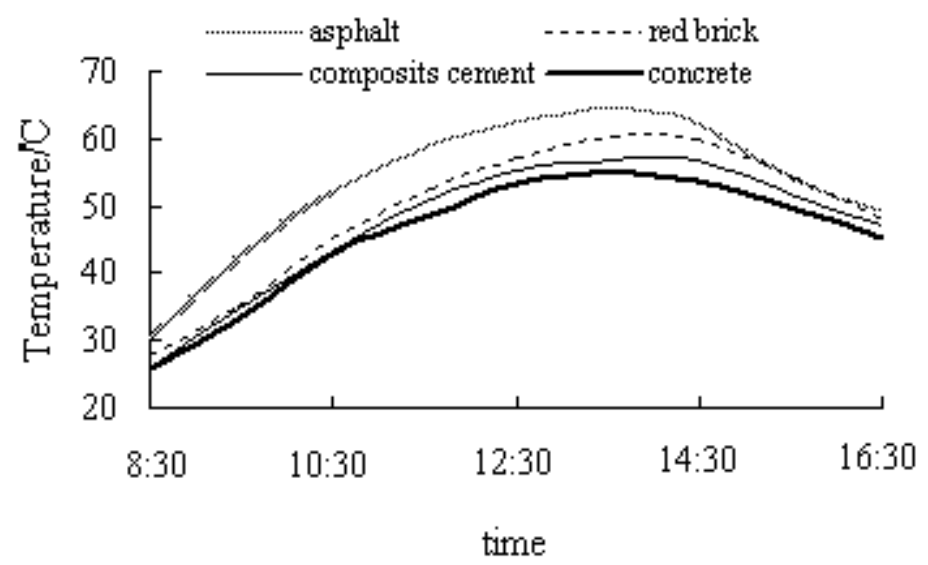

Fig. 6 Temperature variation diagram of the bottom surface of the road slab

In addition, the fluctuations in solar radiation intensity that appeared after 14:30 in the figure were caused by the appearance of clouds. When the solar radiation intensity immediately decreased due to the cloud, the surface temperature also had a subsequent drop fluctuation. Furthermore, the bottom temperature was only slightly affected by the large thermal capacity of the solid slab and there was no temperature fluctuation in Fig. 6. In the four slab materials, clear temperatures differences existed. Among them, the surface temperature of the asphalt slab was the highest, followed by the red brick and composite cement, and the concrete slab exhibited the lowest surface temperature. Generally, the darker the material color, the stronger its thermal absorptance is. In the test, the surface color played a key role in the heat transfer. Of the test materials, the asphalt was black, the brick was red, the composite cement was dark gray, and the concrete slab was light gray; thus, temperature differences occurred. Furthermore, the temperature is influenced by conduction and convective heat transfer, and a slower increasing surface temperature is induced by the higher heat conductivity .

The asphalt slab had the strongest solar radiation absorption. In contrast, during the increasing-temperature period, the change in the upper surface temperatures was slightly greater than that of the bottom temperatures, whereas in the following decreasing-temperature period, it was opposite. Due to the decreasing solar radiation intensity and ambient temperature in the afternoon, the upper surface temperature responses were more rapid, and the bottom temperature responses were slowly due to the thermal inertia.

\subsection{Analysis of absorption characteristics}

Considering the heat absorption of the road from solar radiation, the study of the light reflection or absorption of the surface is necessary. In other words, the heat absorption capacity is limited by the surface spectral absorption. Therefore, the spectrum analysis of the light reflection or absorption was used to scale the heat absorption.

\subsubsection{Reflectance spectral intensity versus material}

The light reflection or absorption on the surface is closely and inversely related to each other. In practice, the 
reflection spectrum was measured during the test because of the reflection spectrum measuring is more convenient, simpler and easier. In fact, a better light absorption indicates a more efficient solar collection, which is related not only to the road surface material and its chromatogram but also to the surface shape.

From Fig. 7, it can be observed that the reflection spectra curves of the four materials increased at first and then decreased, and the corresponding wavelength is basically the same when the wave phenomenon occurs. In the four materials, the response of their reflection spectra was primarily focused on more than $80 \%$ of the radiation energy in the visible wavelength. At a wavelength of $620 \mathrm{~nm}$, the reflection light intensity reached its maximum. The reflection light intensities of the asphalt, red brick, composite cement and concrete were 3363, 8013, 10679 and 11926, respectively. The count was used as the special unit of light intensity in the optical spectrometer. Clearly, the reflection light intensity of the concrete slab was the highest and that of the asphalt slab was the lowest. In this experiment, the maximum reflection light intensity of the asphalt was lower by $58 \%, 68.5 \%$ and $71.8 \%$ than that of the red brick, composite cement and concrete, respectively. Therefore, the asphalt slab had the highest capacity to absorb solar radiation, which was identical to the temperature trend in the preceding analysis. In addition, as shown in Fig. 7, several light intensity fluctuations occurred due primarily to the floating cloud.

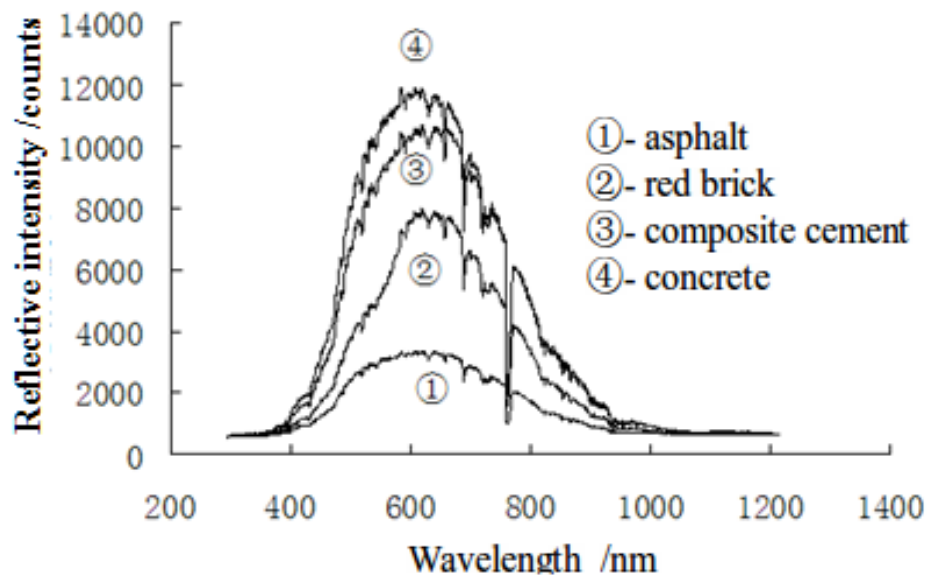

Fig. 7 Surface reflection spectra of different materials

The spectrogram not only shows the peak of reflection of the light intensity but also describes the width of a segment near a peak. The reflection spectrum curve was relatively flat in the asphalt surface and had the greatest ability to absorb radiation (Fig. 7, curve (1), which implied that it not only had a lower intensity but also remained approximately the same size over a wide wavelength range. On the contrary, the other three curves of the spectrogram were more pointed, which indicated that their absorption spectrum ranges were relatively narrow and had a relatively small absorption capacity. Therefore, the best material for a slab solar collector should have a low reflection or a high absorption light intensity and a spectrum peak with a large range.

\subsubsection{Variation of reflected spectral intensity with radiation intensity}

Furthermore, an experiment on different solar radiation intensities was performed to develop the spectrum analysis using the compound cement slab as the example. As shown in Fig. 8, the experiment was tested under three radiation intensities, $187 \mathrm{~W} / \mathrm{m}^{2}, 240 \mathrm{~W} / \mathrm{m}^{2}$ and $260 \mathrm{~W} / \mathrm{m}^{2}$. The greater the solar radiation intensity, the larger the reflection light intensity of the composite cement was. To further analyze the thermal absorption from solar radiation, the growth ratio of intensity was defined to express the influence of solar radiation. In this experiment, a radiation intensity of $187 \mathrm{~W} / \mathrm{m}^{2}$, was selected as the benchmark, and thus, the growth ratios of the other two reflection light intensities were obtained by directly comparing the solar radiation intensities of $240 \mathrm{~W} / \mathrm{m}^{2}$ and $260 \mathrm{~W} / \mathrm{m}^{2}$ with that of $187 \mathrm{~W} / \mathrm{m}^{2}$, as shown in Fig. 9. 


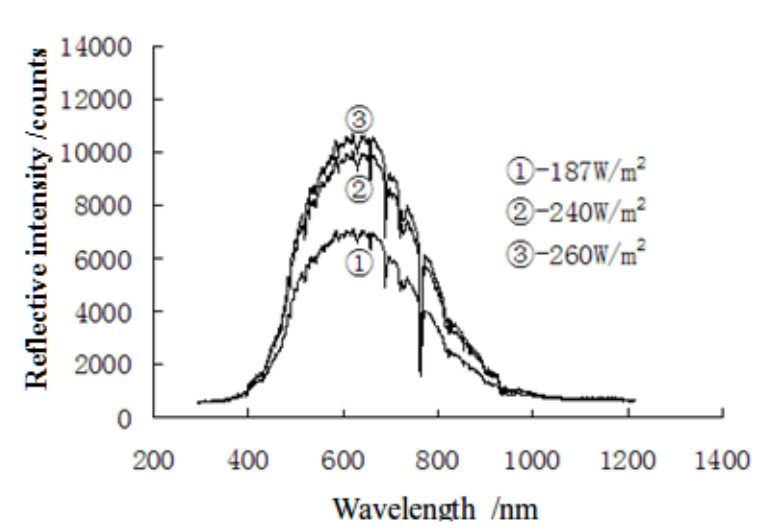

Fig. 8 Surface reflection spectra of concrete at different radiation intensities

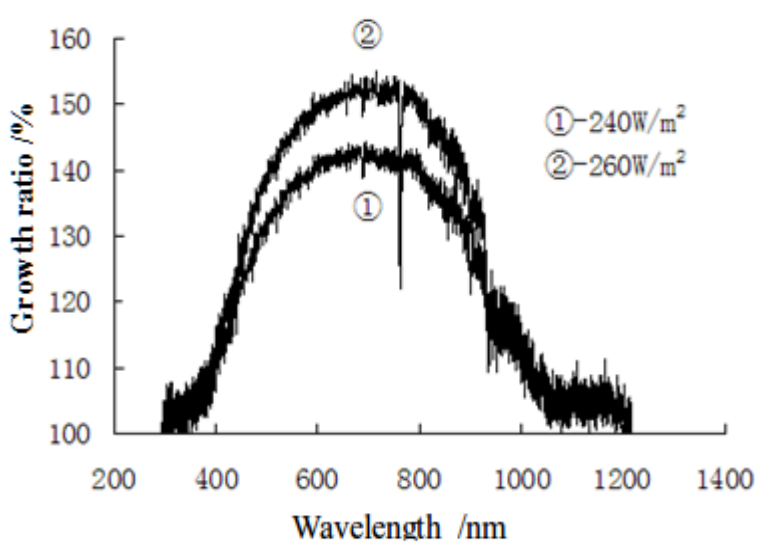

Fig. 9 Growth ratio of the reflection light intensities

The growth ratios increased at first and then decreased as the wavelength increased, where the most effective growth ratio range was between $400-900 \mathrm{~nm}$. Using the benchmark, the average growth ratios of the reflection light intensity with solar radiation intensities of $240 \mathrm{~W} / \mathrm{m}^{2}$ and $260 \mathrm{~W} / \mathrm{m}^{2}$ were $122.3 \%$ and $127.7 \%$, respectively. However, at the same time, the average growth ratios of the solar radiation intensity were $128.3 \%$ and $139.0 \%$ for the two intensities, respectively. From the aforementioned description, it is clear that the growth ratio of the reflection light intensity is correspondingly less than that of the solar radiation. Actually, the reflection light intensity increased as the solar radiation increased; however, the growth ratio of the reflection light intensity was less than that of the solar radiation. Thus, the slab solar collector with the lower growth ratio of reflection light intensity will have a much larger growth potential to absorb more solar energy, which means that improvement depends on changing the growth ratio of solar radiation.

\section{Collected heat analysis}

The collected heat test (Fig. 3) was performed on a sunny day, and the selected test time was from 8:30 AM to 4:30 PM in Changchun, northeast China on August 21, 2009. The flow rate of the working fluid was determined to be 200 $\mathrm{L} / \mathrm{h}$. The solar radiation intensity was approximately $300 \mathrm{~W} / \mathrm{m}^{2}$ to $970 \mathrm{~W} / \mathrm{m}^{2}$, and the ambient temperature was approximately $18^{\circ} \mathrm{C}$ to $23^{\circ} \mathrm{C}$ during the test days.

\subsection{Collected heat capacity}

As mentioned above, an analysis was also performed to study the collected heat with different surface configurations; the results of the collected heat capacity were based on a flowrate of $200 \mathrm{~L} / \mathrm{h}$ with the same pipe spacing interval of $100 \mathrm{~mm}$, as shown in Fig. 10. The peak collected heat of the three types of surfaces (black coating, grooved and smooth, differed greatly), are $351 \mathrm{~W} / \mathrm{m}^{2}, 259 \mathrm{~W} / \mathrm{m}^{2}$ and $244 \mathrm{~W} / \mathrm{m}^{2}$, respectively. Clearly, the road slab solar collection system with a natural, smooth cement surface had the smallest collected heat capacity, where the quantity was much less than that of the black coating, smooth cement surface by approximately $40 \%$. Therefore, the road surface absorbency of a solar heat collector is extremely important. The black coating or the surface modification by additives can collect more heat and reach a considerable collected heat capacity, greater than $250 \mathrm{~W} / \mathrm{m}^{2}$. In addition, the use of grooved or rough surfaces for mechanical and physical treatment of the surface can also improve heat collection capacity. Thus, a suitable and formal treatment is necessary. 


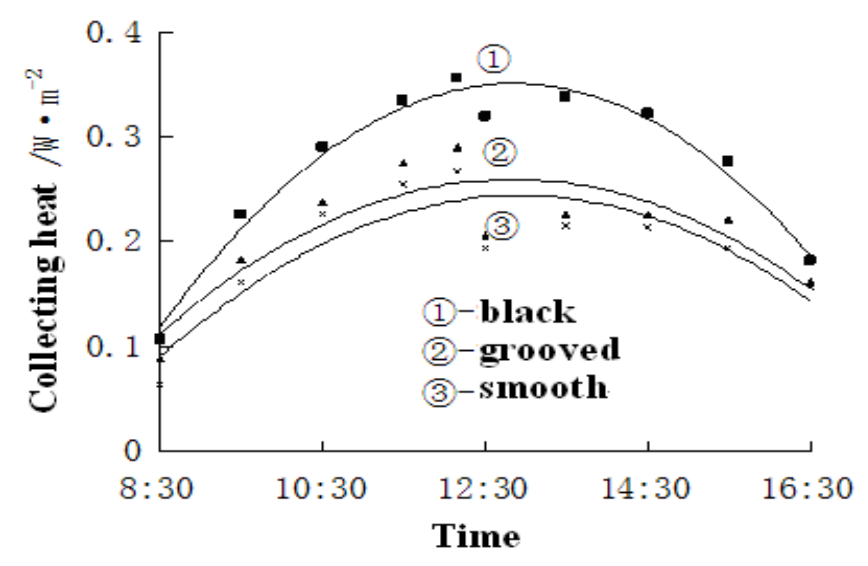

\subsection{Collected heat efficiency}

Fig. 10 Collected heat capacity of per surface area

The collected heat effect can be judged from the collected heat efficiency. In general, the collected heat efficiency indicates the effective ability of a solar collector to absorb solar energy, which can be expressed as a percentage of collected heat to the all the real solar radiation.

Fig. 11 shows the variation in the collected heat efficiency for different surface configurations. For the three types of surfaces, black coating, grooved and smooth, their average collected heat efficiency had several differences, i.e., $38.4 \%, 30.1 \%$ and $27.7 \%$, respectively. The collected efficiency also proved that blackening and coarsening surface is a way to collect more heat and attain a higher efficiency.

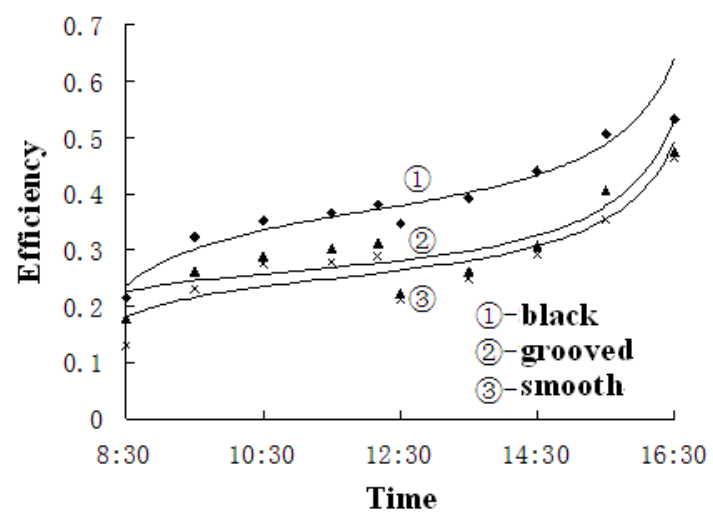

Fig. 11 Collected heat efficiency

From Fig. 11, the results indicate that the collected heat efficiency increases with solar intensity but the trend is not similar to the variation in the solar intensity. When the solar radiation intensity increased during the period before noon, both the absorbed heat and the efficiency increased. And when the solar radiation intensity weakened in the afternoon, the efficiency also increased due to the heat transfer hysteresis and solar radiation attenuation. The large heat capacity of solid structure collector plays a leading role in heat transfer hysteresis and the decrease of radiation are rapidly. However, a solid-structure collection heat system, such as a road, has a large thermal capacity and results in a heating lag, where the thermal capacity and the faster attenuation of solar radiation intensity are the primary factors, which results in the rapid increase of the collected heat efficiency.

\subsection{Surface temperature}

Surface temperatures indicate how well the working fluid absorbs heat in the hydronic pipe imbedded in a road under sunlight. The surface temperature has several expressive significations. The surface temperature expresses the effect of the operation factors, road material, surface configuration, pipe arrangement, etc. A higher surface temperature indicates a higher thermal absorption of sun radiation of the road surface and can also indicate if solar radiation energy is 
not effectively absorbed by the fluid. In the present work, the surface temperatures were used to evaluate the thermal radiation absorption by use of surface treatment of the solar collector, and the center point was selected for further identification and analysis, as shown in Fig. 12. The figure shows the surface temperatures from the three surfaces, i.e., black coating, smooth and grooved. From the experiments, it was shown that the temperature variations follow the sunlight intensity, increasing at first and then decreasing during the one-day test. The basic temperature variation was the same as the variation in the solar radiation intensity. However, the three surface configurations resulted in different temperature levels. The maximal peak value of the surface temperatures of the black coating, smooth and grooved surfaces were $49.3^{\circ} \mathrm{C}, 46.5^{\circ} \mathrm{C}$ and $45.0^{\circ} \mathrm{C}$, respectively, and occurred approximately 14:00 PM.

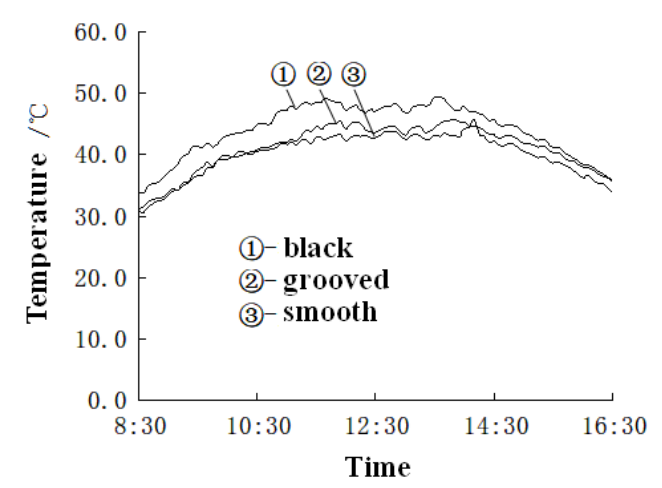

Fig. 12 Surface temperature

Clearly, the temperature of the black surface was the highest, with the lowest temperature being for the smooth surface. Furthermore, it can be observed that there was a large temperature level difference due to the color of the surface, similar to the collected heat capacity and its efficiency. Thus, a suitable color with a coarse configuration can collect more heat with a higher efficiency and higher surface temperature. Undoubtedly, the heat quantity and fluid temperature level result from the surface temperature during a solar collection process. The heat quantity and fluid temperature level is closely related to the operation control of the temperature level and the distribution energy in the UTES [25].

Additionally, the size of the surface temperature of each solar collector panel is a direct response to the heat collection effect for the same solar radiation intensity, operating parameters and connection piping works. Based on the number of heat collectors and heat collection efficiency in Figure 10 and Figure 11, it can be seen that a higher surface temperature of the road panels also implies a larger number of heat collectors and heat collection efficiency.

\section{Conclusions}

Solid solar collectors can absorb large amounts of solar radiation and provide a huge potential energy source for snow melting systems with seasonal thermal energy storage. It is of great importance for the sustainable development of the energy environment in the future.

The experimental results show that the color of the material of the pavement layer plays a major role in the absorption of solar radiation. Asphalt slabs have a larger surface temperature compared to red brick, composite cement and concrete. The surface temperature of asphalt slabs is $8.1 \%, 14.9 \%$ and $16.4 \%$ greater than the other three slabs, respectively. However, at the same time, the bottom surface temperature of the asphalt slab decreased the fastest among the three.

It can also be seen from the above description that the intensity of the reflection spectrum can be used to describe the absorption performance of the collector. From the experimental analysis, it can be concluded that at the same radiation intensity, the surface reflectance spectral intensity of the four materials is highest for concrete, followed by composite cement and brick, and lowest for asphalt.

In addition, taking composite cement as an example, as the radiation intensity increases, the reflectance 
spectral intensity also increases, but the rate of increase of reflectance spectral intensity is lower than the rate of increase of radiation intensity. A low reflectance spectral intensity will correspondingly have a higher absorption spectral intensity with a higher heat collection capacity, so it is particularly important for solid collectors to choose materials with a lower reflectance spectral intensity growth rate.

In fact, the better the absorption performance, the higher the collector collector efficiency, which is not only related to the collector's material and chromatography, but also to its surface properties. In the experiments of composite cement, respectively, using black coating, grooves and smooth three surfaces, it can be seen that the size of the three collector heat and collector efficiency are black coating > groove surface > smooth surface; and the impact of black coating is greater than the impact of grooves.

In addition, it can also be seen from the experiment that the heat collection efficiency of the collector does not change simultaneously with the change of heat collection, which is because the absorbed heat and thermal efficiency increase when the intensity of solar radiation increases before noon. When the intensity of solar radiation decreases after noon, the actual heat absorption of the solid structure slowly decreases due to the rapid decrease in the radiation input from the solar radiation intensity, and therefore the thermal efficiency increases. However, the large heat capacity of solid structure heat collection systems such as roads causes a lag in heat supply, where the heat capacity and the faster decay of solar radiation intensity are the main factors, resulting in a rapid increase in heat collection efficiency.

\section{Acknowledgment}

The authors are grateful for support provided by Newton Fund UK-China Industry Academia Partnership Programme scheme (UK-CIAPPI201), Jilin Province Science and Technology Development Programme scheme (20180414021GH) and Education Department of Jilin Province Higher Education Teaching Reform Project (2019XZD038).

\section{References}

[1] Ballari MM, Brouwers HJH. Full scale demonstration of air-purifying pavement. J Hazard Mater 2013;254:406-14.

[2] Hassan M, Mohammad LN, Asadi S, Dylla H, Cooper III S. Sustainable photocatalytic asphalt pavements for mitigation of nitrogen oxide and sulfur dioxide vehicle emissions. J Mater Civil Eng 2012;25(3):365-71.

[3] Osborn D, Hassan M, Asadi S, White JR. Durability quantification of TiO2 surface coating on concrete and asphalt pavements. J Mater Civil Eng 2013;26(2):331-7.

[4] Gallus M, Akylas V, Barmpas F, Beeldens A, Boonen E, Boréave A, et al. Photocatalytic de-pollution in the Leopold II tunnel in Brussels: NOx abatement results. Build Environ 2015;84:125-33.

[5] Wendel, Ion L. Paving and Solar Energy System and Method. United States Patent, 4132074, 1979-01-02.

[6] P.B.L. Chaurasia. Solar Water Heaters Based on Concrete Collectors. Energy. 25 (8), 2000: 703-716.

[7] Gao Yiping. Snow Melting on the road by Solar Energy Application. Journal of Foreign Highway, 17 (4) , 1997: 53-55.

[8] E. Bilgen And M.A. Richard, Horizontal Concrete Slabs As Passive Solar Collectors, Solar Energy, 72(5), 2002: 405-413.

[9] Walter J. Eugster, Jürg Schatzmann. Harnessing Solar Energy for Winter Road Clearing On Heavily Loaded Expressways. Proceeding of XIth PIARC International Winter Road Congress, January 2002, Sapporo, Japan.

[10] Rees S J, J D Spitler, X Xiao. Transient Analysis of Snow-melting System Performance. ASHRAE Transactions, 108(2), $2002: 406-423$.

[11] D Derwin, PBooth, PZaleski, etal. SNOE FREE-Heated Pavement System to Eliminate Ice Runways. SAE technical paper series 2003-01-2145, 2003.

[12] Gordon, S. Energy from the Ground Up [Interseasonal Heat Transfer]. Power Engineer. 19(4), 2005:20-23. 
[13] Sullivan C.G., De Bondt A., Rob Jansen, Henk Verweijmeren. Energy from Asphalt Pavements. International Conference on Sustainable Construction Materials and Technologies, Supplementary proceedings, Coventry, UK, June 2007: 102-109.

[14] Carder D R, Barker K, Hewitt M G, Ritter D and Kiff A. Performance of an interseasonal heat transfer facility for collection, storage, and re-use of solar heat from the road surface. TRL's Published Project Report PPR302, 2008.3.

[15] Mallick Rajib B, Chen Bao-Liang, Bhowmick Sankha, Michael S Hulen, Capturing Solar Energy from Asphalt Pavements. Paper publication of International Society for Asphalt Pavements, 2008.8.

[16] Wu Shaopeng, Chen Mingyu, Zhang Jizhe. Laboratory investigation into thermal response of asphalt pavements as solar collector by application of small-scale slabs. Applied Thermal Engineering 31 (2011) 1582-1587.

[17] Vanesa Bobes-Jesus, Pablo Pascual-Muñoz, Daniel Castro-Fresno, Jorge Rodriguez-Hernandez, Asphalt solar collectors: A literature review, Applied Energy 102 (2013) 962-970.

[18] P. Pascual-Muñoz, D. Castro-Fresno, J. Carpio, D. Zamora, Barraza. Influence of early colour degradation of asphalt pavements on their thermal behaviour, Constr. Build. Mater. 65 (2014) 432-439.

[19] Alejandro Alonso-Estébanez, Pablo Pascual-Muñoz, José Luis Sampedro-García, Daniel Castro-Fresno, 3D numerical modelling and experimental validation of an asphalt solar collector, Applied Thermal Engineering 126 (2017) 678-688.

[20] Richard O'Hegartya, Oliver Kinnaneb, Sarah J. McCormacka, Concrete solar collectors for façade integration: An experimental and numerical investigation, Applied Energy 206 (2017) 1040-1061.

[21] Anne Mäkiranta,Erkki Hiltunen. Utilizing Asphalt Heat Energy in Finnish Climate Conditions[J]. Energies,2019,12(11).

[22] Caner Çuhac,Anne Mäkiranta,Petri Välisuo,Erkki Hiltunen,Mohammed Elmusrati. Temperature Measurements on a Solar and Low Enthalpy Geothermal Open-Air Asphalt Surface Platform in a Cold Climate Region[J]. Energies,2020,13(4).

[23] Jose L. Concha, Jose Norambuena-Contreras. Thermophysical properties and heating performance of self-healing asphalt mixture with fibres and its application as a solar collector. 2020, 178.

[24] C. D. Galatanu and L. Canale, "Measurement of Reflectance Properties of Asphalt using Photographical Methods," 2020 IEEE International Conference on Environment and Electrical Engineering and 2020 IEEE Industrial and Commercial Power Systems Europe (EEEIC / I\&CPS Europe), Madrid, Spain, 2020, pp. 1-6.

[25] Qing Gao, Ming Li, Ming Yu, Spitler, Jeffrey D., Y.Y Yan. Review of development from GSHP to UTES in China and other countries. Renewable and Sustainable Energy Reviews, 13(6-7), 2009:1383-1394. 